Niğde Ömer Halisdemir Üniversitesi Mühendislik Bilimleri Dergisi
Niğde Ömer Halisdemir University Journal of Engineering Sciences

\title{
Sürdürülebilir işgücü çizelgeleme ve rotalama probleminin değişken komşu arama algoritmasıyla çözümü: Samsun örneği
}

\author{
The Sustainable workforce scheduling and routing problem with variable \\ neighbourhood search algorithm: The case of Samsun
}

\author{
Mehmet Erdem ${ }^{1, *}$ \\ ${ }^{1}$ Ondokuz Mayls Üniversitesi, Endüstri Mühendisliği Bölümü, 55139, Samsun Türkiye
}

$\ddot{O} z$

$\mathrm{Bu}$ çalışmada sürdürülebilir işgücü çizelgeleme ve rotalama problemi (S-İÇR) ele alınmıştır. Problemde farklı yetkinlik seviyesine sahip çalışanlardan takımlar oluşturularak farklı ilçelerde bulunan müşterilere önceden belirlenmiş zaman dilimi içerisinde hizmet verilmektedir. Problem için tam sayılı doğrusal programlama modeli geliştirilmiş olup model araç rotalama, işgücü çizelgeleme, araç şarj durumu takibi ve şarj istasyonu ziyareti gibi kararlar da gözetilmiștir. Ayrıca farklı amaç fonksiyonları göz önüne alınarak toplam mesafenin yanı sıra, araç maliyeti de dikkate alınmıştır. Yapılan deneysel çalışmalar bize elektrikli araçların bakım hizmeti sağlayan firmalarda günlük kullanılabilirliğini göstermiștir. Ayrıca geliștirilen değişken komşu arama (DKA) algoritmasının performansı kesin çözüm yöntemiyle karşılaştırılmış ve sonuçlar önerilen yöntemin iyi çözüm bulmadaki etkinliğini göstermiştir.

Anahtar kelimeler: Elektrikli araçlar, İşgücü çizelgeleme, Matematiksel programlama.

\section{Giriș}

Ulaşım sektörünün kalkınmaya, büyümeye ve istihdama olan katkısı yadsınamaz bir gerçektir [1-3], fakat sektörün negatif çevresel etkileri konusunda da farkındalık artmaktadır [4]. Araştırmacılar iklim değişikliğinin etkilerini en aza indirmek ve kısıtlı miktardaki fosil yakıt bağımlılığını azaltmak için farklı öneriler getirmektedir. Bu sebepten dolayı kural koyucular bu sorunların çözümü için hedefler belirlemektedir. Ulaşım sektörü toplam sera gazı miktarın \%20'sini ürettiği bilinmektedir [5]. Bu sebepten ötürü, Avrupa Birliği, sera gazının 2020 yılına kadar \%20, 2030 yılına kadar \%40 azaltmayı hedeflemektedir [6]. Sehirlerde kullanılan içten yanmalı motorlu araçların kullanımıyla ilgili tartışmalar konunun önemini de vurgulamaktadır [7]. Elektrikli araçlar (EA) yukarıda bahsi geçen problemlere çözüm olarak ortaya çıkmaktadır. UPS, DHL, FedEx, General Electric ve Coca-Cola gibi firmalar lojistik operasyonlarında elektrikli lojistik filo kullanılmaya çoktan başlamıștır [8, 9]. Bu araçların sıfır emisyona sahip olması, gürültü seviyesinin düşük olması, içten yanmalı motora göre daha az bakım maliyeti gerektirmesi vb. avantajlarından

\begin{abstract}
This paper addresses sustainable workforce scheduling and routing problem (WSRP), in which technicians with different levels of competence are paired into teams to serve customers in different geographic regions-districts within predetermined time windows. We formulate the WSRP as a mixed integer linear programming formulation that covers the decisions such as scheduling, routing, state of charge, and visiting of the charging stations. Furthermore, we developed different objective functions minimizing not only total travelled distance, but also the number of electrical vehicles employed. The performance of the proposed heuristic is tested by using real-world data. In addition, the developed variable neighbourhood search algorithm is compared with the exact solution method and the computational results indicates that the proposed heuristic can yield high quality of solutions.
\end{abstract}

Keywords: Electric vehicles, Workforce scheduling, Mathematical programming.

ötürü sürdürülebilirlik açısından büyük bir firsat olarak görülmektedir.

$\mathrm{Bu}$ çalışmada tek periyotlu sürdürülebilir işgücü çizelgeleme ve rotalama problemi (S-ICCRP) ele alınmıştır. Problemde bakım hizmeti sağlayıcısından farklı ilçelerde konumlanmış müşteriler, bir dizi düzeltici ve önleyici bakım, arıza teşhisi ve yedek parça teslimatı gibi hizmet talep etmektedir. Hizmet sağlayıcısı firma bu hizmetleri farklı kalifiye teknisyenlerden oluşturduğu takımlarla müşterilerin bulunduğu lokasyonlarda sunmaktadır. Takımlar müșterilere ulaşmada mevcut literatürün aksine klasik içten yanmalı motorlu araçları değil çevreci elektrikli araçları kullanmaktadırlar. Ayrıca bu araçlara ait maliyetler de göz önüne alınmıştır. Yapılan çalışmanın literatüre katkıları şunlardır:

- Elektrikli araçlar gözetilerek tek periyotlu sürdürülebilir işgücü çizelgeleme ve rotalama problemi (SİCRP) modellenmiş olup mevcut literatürle ilisskisi tanımlanmıştır.

- Gerçek hayat verisi kullanarak deneysel hesaplamalar yapılmıș olup ayrıca önerilen çözüm yönteminin performansı da değerlendirilmiştir.

\footnotetext{
* Sorumlu yazar / Corresponding author, e-posta / e-mail: mehmet.erdem@omu.edu.tr (M.Erdem)

Geliş / Recieved: 11.03.2021 Kabul / Accepted: 11.01.2022 Yayımlanma/ Published: 15.04.2022

doi: $10.28948 /$ ngmuh. 895487
} 
- Sezgisel yöntemin iyi sonuçlar ürettiği de gözlemlenmiştir.

Çalışmanın bu aşamadan sonraki takip eden kısımları sırasıyla şu şekilde düzenlenmiştir. İlk önce literatür incelenecek, sonraki kısımda probleminin tanımı ve formülasyonu verilecek, aynı kısımda önerilen sezgisel çözüm yöntemi sunulacak, dördüncü kısımda deneysel hesaplama sonuçları analiz edilecek ve son kısımda ise elde edilen sonuçlardan bahsedilecektir.

Personel çizelgeleme problemi birçok araştırmacı tarafindan farklı üretim ve hizmet sektörlerine uygulanagelmiştir [10-12]. Problemin karmaşık yapısı gereği uygun personelin seçimi ve atanması, izin planlama, vardiya yönetimi vb. farklı aşamaların göz önüne alınması gerekmektedir. Problem ayrıca talep modelleme, izin günü planlama, vardiya çizelgeleme, iş hattı yapımı, görev atama ve personel atama olarak siniflandirılmaktadır [11]. Bu çalışmada ele alınan problem personel atama sınıfına dâhil edilebilir.

Castillo-Salazar, vd. [13] İÇRP hakkında literatür araştırması yaparak farklı alanlardaki çalışmaları sınıflandırmış ve genel karakteristiklerini ortaya koymuşlardır. Evde bakım/sağlık hizmetleri, teknisyen çizelgeleme, güvenlik personeli rotalama ve çizelgeleme ve iş gücü atama problemlerini sınıflamışlar ve incelemişlerdir. Cordeau, vd. [14] teknisyen ve iş çizelgeleme problemini göz önüne almışlardır. Problemde belirli görevler için birden fazla çalışanın yetkinlik seviyesine göre atanması göz önüne alınmıştır. Ele alınan tek periyotlu problemde amaç tüm işlerin tamamlanma zamanını minimize etmektir. İşlerin gereksinimi, işlere ilişkin öncelik sıralamaları, teknisyen uygunluğu ve çalışma saatine ilişkin kısıtlar modelde dikkate alınmıştır. Problemde rotalama kararı ise göz ardı edilmiştir. Kovacs, vd. [15] teknisyen ve iş çizelgeleme probleminde rotalama kararını dikkate alarak teknisyen rotalama ve çizelgeleme problemini tanımlamıştır. Cordeau, vd. [14]'nin ele aldığı probleme benzer şekilde bakım görevleri için ekiplerin oluşturulması için farklı beceriye sahip teknisyenler modele dâhil edilmiştir. Problemde amaç talep edilen hizmetleri belirli zaman penceresi içinde yerine getirmek ve seyahat masraflarını en aza indirmektir. Problemde takımlar farklı boyutlara sahip olabildiği gibi işlerde yapılmayabilir. Her iki çalışmada uyarlanabilir büyük komşu arama (UBKA) ile çözüm yöntemi geliştirilmiştir.

Lim, vd. [16] zaman pencereli işgücü atama problemi ele almışlardır. Çalışma bir limanda istihdam edilen çalışanların bir dizi farklı görevler için atanmasını konu almaktadır. Modelin amacı atanan çalışan sayısının, toplam mesafenin, bekleme zamanının minimize edilmesinin yanı sıra yapılan işlerin sayısının artırılmasıdır. Çalışanların benzer tecrübe seviyesine sahip olduğu kabul edilmiştir. Problemin çözümü için tabu arama ve tavlama benzetiminden oluşan bir sezgiselin yanı sira yerel arama tabanlı bir algoritma geliştirilmiştir. Li, vd. [17] benzer bir problem üzerinde çalışmış ve takım oluşturma kısıtı eklemişlerdir. Problemin amacı toplam seyahat zamanının ve toplam çalışan sayısının minimizasyonudur. Problem için çözüm kurucu sezgisel önerilmiş ve tavlama benzetimi ile iyileştirilmeye çalışılmıştır. Havalimanı yer hizmetleri görevlerinde benzer iş gücü atama problemi için Dohn, vd. [18] tam sayılı programlama modeli sunmuşlardır. Dal-Ücret algoritmasına dayalı çözüm yöntemi ile problem çözülmüştür. Xu ve Chiu [19] telekomünikasyon sektöründeki bir servis sağlayıı için benzer bir problemi ele almışlardır. Geliştirilen modelde amaç teknisyenlerin yetkinlik seviyelerini maksimize ederek kalifiye personelin atanma olasılığını artırmaktır. Pillac, vd. [20] benzer bir problemi ele alarak teknisyenin yetkinliğinin yanı sıra kullandığı alet ve elindeki yedek parçaları da dikkate almışlardır. Teknisyenlerden takım oluşturma ise yine göz ardı edilmiştir. Problemin çözümünde paralel UBKA algoritmasını kullanmışlardır. Zamorano ve Stolletz [21] periyodik teknisyen rotalama ve çizelgeleme problemini ele alarak dal-ücret algoritmasını problemin çözümünde uygulamışlardır. Ayrıca, yöntemin performansı gerçek hayat verisi ile test edilmiştir. Erdem [22] benzer periyodik teknisyen rotalama ve çizelgeleme problemini ele alarak çalışanların yasal dinlenme sürelerini de gözetmiştir. Ayrıca önerilen modelde çalışanların kullandığı elektrikli araçlar için şarj istasyonu yeri seçimi dikkate alınmıştır. Zamorano ve Stolletz [21] tarafindan çözülen ufak boyutlu problemler yerine çalışmada daha büyük boyutlu örnekler çözülmüştür.

Klasik araç rotalama probleminde (ARP) kullanılan araçlar içten yanmalı motora sahiptir. Erdoğan ve MillerHooks [23] mevcut teknoloji yerine çevreci/yeşil motorlu araçları bu problemde ilk olarak kullanmışlardır. Alternatif yakıt kullanan araçlar yerine elektrikli araçlar kullanarak, Schneider, vd. [24] elektrikli zaman pencereli ARP (EZPARP)'yi geliştirmişlerdir. Bu problemde araçların enerji ikmali için harcanan uzun süre ve şarj istasyonu önemli ve problemi karmaşıklaştıran sorunlardandır. Bundan dolayı müşteri lokasyonunda araçların şarj olması da bazı çalışmalara dâhil edilmiştir [25]. Elektrikli araçlar, şarj için önemli bir süreyi boşta geçirmektedirler bu sebepten ötürü boş bataryanın dolu batarya ile değiştirilmesini dikkate alan çalışmalar şarj süresini sabit kabul etmişlerdir [23, 25, 26]. Benzer şekilde ful şarj politikası izleyen diğer çalışmalar ise araçların istasyondan \%100 şarj ile hareket ettiğini varsaymıştır [24, 27-29]. Bu durum pek gerçekçi değildir çünkü kısıtlı zamanın etkin kullanımını etkilemektedir. Bu çalışmalardan farklı olarak şarj süresinin negatif etkisini azaltmak için kısmi şarj çoğu çalışmada dikkate alınıp, modele karar değişkeni olarak eklenmiştir [8, 30-32]. Elektrikli ticari araçların mal dağıtımı ve pil karakteristikleri hakkında kapsamlı bilgi için Pelletier, vd. [33] ve Pelletier, vd. [34]'nin çalışmaları incelenebilir. E-ZPARP çözümünde genelde sezgisel algoritmalar kullanılmıştır. Bunlar kısaca bahsetmek gerekirse: tabu arama-değişken komşu arama algoritmalarından oluşan hibrit bir sezgisel [24], UBKA [29, 31,35 ] ve tavlama benzetimi [30]. Ayrica, Desaulniers, vd. [28] farklı E-ARP problemleri için bir dal-ücret-kes yöntemiyle kesin çözüm yaklaşımı sunmuşlardır.

Sonuç olarak ele alınan problemde bir dizi çalışandan takım oluşturulması, takımların işlere belirlenen yeterlilik seviyesi gözetilerek atanması, takımların kullandığı çevreci elektrikli araçların rotasının belirlenmesi, bu araçlara ait şarj durumunun takibi ve şarj gerekirse nerede ve ne zaman şarj olacağı göz önüne alınan diğer kararlar arasındadır. Ayrıca elektrikli araçların kullanımıyla avantajlar bulunmakla 
beraber kısıtlı menzili, şarj olma süresinin uzunluğu ve şarj istasyonu alt yapısının mevcudiyeti vb. konular da planlamada dikkate alınması gerekmektedir. Yapılan çalışmada matematiksel olarak tanımlanan problem için karma tam sayılı lineer programlama formülasyonu geliştirilmiştir. Ayrıca, çözüm için değişken komşu arama (DKA) sezgiseli geliştirilerek makul zamanda etkin çözüm vermesi sağlanmıştır.

\section{Materyal ve metot}

Sürdürülebilir işgücü çizelgeleme ve rotalama problemi (S-İÇRP) Şekil 1'deki gibi örneklendirilmiştir. On müşteri, üç istasyon ve iki depoyu içeren örnekte, yüzdelik değerler araçların ilgili düğüme vardığında ve ayrıldığındaki şarj seviyesine karşılık gelmektedir. Müşteri istekleri önceden belirli olup günün belirli bir zaman diliminde gerçekleşmesi gerekmektedir. Koyu renkteki köşeli parantez içindeki rakamlar ilgili müşterinin zaman penceresini ve parantez içindeki değer ise işin süresini ifade etmektedir. Ayrıca her müşteri isteği en fazla bir takım tarafından yerine getirilmesi gerekmektedir ve tüm işler ifa edilmelidir. Her bir takım belirlenen sayıda teknisyenden oluşmaktadır ve takımlar talep edilen işleri yapmak için tek tip-homojen elektrikli araç kullanmaktadır. Farklı bölgelerde bulunan depolardan hareket eden takımlar yine tanımlanan mesai saati içinde hizmet verebilmektedir. Takım 1 müşteri 10'a uğradıktan sonra depoya dönerken şarj istasyonuna uğramış, takımın kullandığı araç istasyona $\% 5$ şarj seviyesi ile girip $\% 80$ şarj seviyesi ile çıkmıştır. Takım 3 şarj istasyonu 3'e iki kere uğramıştır. Takım 2 ise şarj istasyonuna uğramaya gerek kalmadan görevini tamamlamıştır. Ayrıca şarj istasyonu 2'ye hiçbir takım uğramamıştır. Servis zamanı, seyahat mesafesi ve yapılması gereken işin gerektirdiği yetkinlik seviyesi önceden bilinmektedir. Teknisyenlerin de sahip oldukları (hidrolik, mekanik, elektrik vb.) birtakım kalifiye eleman özellikler mevcuttur. Başka bir deyişle takımın kalifiye seviyesi, teknisyen kalifiye seviyesinin birleşiminden oluşmaktadır. Problemin matematiksel modeli için gösterimi ve formulasyonu sırasıyla verilmiştir.

$\mathrm{Bu}$ problem iş kümesi $B$, şarj istasyonu kümesi $F$, iki farklı depoya ait düğümlerden oluşmaktadır. Ayrıca, küme $N$, müşteri kümesi $B$ ve birden fazla şarj istasyonuna izin veren $F^{`}$ olarak tanımlanmaktadır. Başlangıç ve bitişi deposu $0_{k}$ ve $n_{k}$ ile gösterilmektedir. Dolayısıyla $N_{0_{k}}\left(N_{n_{k}}\right)$ başlangıç ve bitiş depolarını içeren tüm düğümleri içerirken, $N_{0_{k}, n_{k}}$ kümesi $N \cup\left\{0_{k}, n_{k}\right\}$ kümesini ifade etmektedir. Benzer gösterim $B$ ve $F^{\prime}$ içinde kullanılmıştır. Problem yönlü ağ yapısıyla ifade edilebilir $G=\left(\bigcup_{k \in T} N_{0_{k}, n_{k}}, A\right)$ ve bu gösterimde $A=\left\{(i, j) \mid i, j \in \cup_{k \in T} N_{0_{k}, n_{k}}, i \neq j\right\}$ yönlü ayrıt kümesini ifade etmektedir. Ayrıca, problemde $m, n \in M$ teknisyen çiftleri bir takıma $k \in T$ atanarak talep edilen bakım görevlerini yerine getirmek için gönderilir. Takımlar bu işlere ulaşmada kullandıkları elektrikli araçlar homojendir. Buna ek olarak, teknisyenlerin ve işlerin yetkinlikleri ve bu yetkinliklerin seviyeleri tanımlanıştır. Yetkinlikler $q \in Q$ kümesi, yetkinlik seviyesi ise $l \in L$ ile tanımlanmıştır.
Rota karar değişkeni $x_{i j k} k$ takımı $i$. düğümden $j$. düğüme giderse 1 değerini, diğer durumda 0 değerini almaktadır $k \in$ $T, i, j \in N_{0_{k}, n_{k}}, i \neq j$. Her bir düğümün zaman penceresi $\left[\alpha_{i}, \beta_{i}\right]$ ile tanımlanmış olup, işlerin tamamlanması için gereken süre ise $d_{i}$ ile tanımlanmaktadır $i \in B$. Aracın düğümler arası seyahat süresi $t_{i j}{ }^{\prime} \operatorname{dir} i, j \in N_{0_{k}, n_{k}}, i \neq j$. Çalışanlara ilişkin mesai saatleri ise $[\alpha, \beta]$ ile tanımlanmaktadır. Çizelge/zaman karar değişkeni $\tau_{i k}, k$ takımının $i$. düğüme varış zamanını ifade etmektedir $k \in$ $T, i \in N_{n_{k}}$.

Takımların kullanmış olduğu elektrikli araçların azami enerji kapasitesi $Y$ ile tanımlanmaktadır ve şarj karar değişkeni $y_{i k} k$ takımının $i$. düğümündeki enerji seviyesini ifade etmektedir $k \in T, i \in N_{n_{k}}$. Ayrıca, $k$ takımının $i$. şarj istasyonundan ayrıldığındaki enerji seviyesi $h_{i k}$ ve $k$ takımının $i$. şarj istasyonundaki şarj süresi $g_{i k}$ ile gösterilmektedir. Araçların tükettiği birim başına enerji ise $r$ ile tanımlanmaktadır. Bunula beraber $\Delta$ parametresi aracın birim zamanda yeniden şarj olmasını miktarını ifade etmektedir (bkz. Tablo 1).

\subsection{Amaçlar}

Ele alınan problem farklı planlama perspektifleri içerebilir, bu sebepten dolayı farklı amaç fonksiyonları kullanılabilir. Literatürde EARP problemleri genelde toplam mesafenin minimizasyonunu dikkate almaktadır. EARP'den farklı olarak şarj istasyonu konum belirleme üzerine yapılan çalışmalarda, amaç işletme maliyeti, araç ve şarj istasyonu yatırım maliyetlerinden oluşmaktadır. Birinci Denklem (1)'de verilen amaç fonksiyonu kat edilen mesafenin maliyetini ifade etmektedir. İkinci Denklem (2)'de ise amaç mesafeye ilişkin maliyetle beraber takımların kullandığı aracın günlük maliyetini teşkil etmektedir. Bu amaçla beraber en az sayıda araçla işlerin yapılması da istenmektedir.

$$
\begin{array}{r}
\text { Min. } \Theta_{1} \sum_{k \in T} \sum_{i \in N_{0_{k}}} \sum_{j \in N_{n_{k}}} c_{i j} x_{i j k} \\
\text { Min. } \Theta_{1} \sum_{k \in T} \sum_{i \in N_{0_{k}}} \sum_{j \in N_{n_{k}}} c_{i j} x_{i j k} \\
+\Theta_{2} \sum_{k \in T} \sum_{j \in N} x_{0_{k} j k}
\end{array}
$$

\subsection{Kısitlar}

Modelin kısıtlarından bu bölümde bahsedilecektir. 3 ve 4. kısıt tüm işlerin bir takıma atanmasını sağlamaktadır. 5 . kısıt şarj istasyonu kullandığı takdirde göz önüne alınacaktır. Araçlar gerek duymadığ uğramayacaktır. Araçların rotaları ait oldukları depolardan başlayıp ait oldukları depolarda bitmelidir (6-7 kısıt). 8. kısıt akış korunumu için tanımlanmıştır. Zaman kısıtları (9-11) ile göz önüne alınmıştır. İşlerin belirlenen zaman penceresi içinde yapılmasını ve çalışanların mesai saatleri (10) ile sağlanmıştır. 10. kısıtta herhangi bir işin başlama zamanı, bir önceki işin işlem süresi ve bir önceki düğümden seyahat süresi dikkate alınarak hesaplanmaktadır. 11. kısıt şarj 
istasyonunu ve şarj süresini dikkate almaktadır. 10. kısıtın 11. kısıttan farkı, bir önceki düğümün şarj istasyonu olması ve şarj süresinin dikkate alınmasıdır.

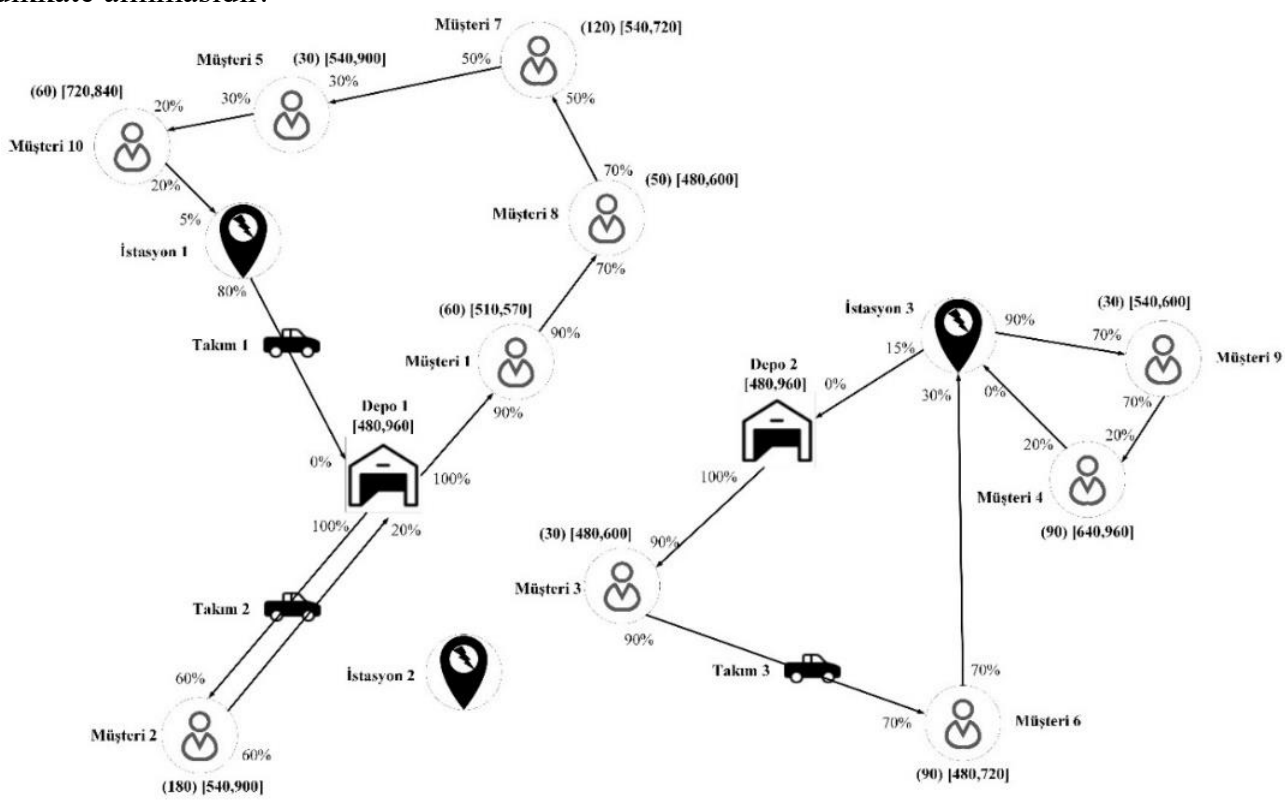

Şekil 1. Problem örneği

Tablo 1. Notasyon (Notation)

\begin{tabular}{|c|c|}
\hline \multicolumn{2}{|l|}{ Kümeler } \\
\hline$B$ & İş kümesi \\
\hline$F$ & Şarj istasyonları kümesi \\
\hline$F^{\prime}$ & Kukla şarj istasyonları kümesi \\
\hline$N$ & $N=B \cup F^{\prime}$ İş ve kukla istasyonları içeren küme \\
\hline$N_{0_{k}}$ & $N_{0_{k}}=N \cup\left\{0_{k}\right\}$ \\
\hline$N_{n_{k}}$ & $N_{n_{k}}=N \cup\left\{n_{k}\right\}$ \\
\hline$N_{0_{k}, n_{k}}$ & $N_{0_{k}, n_{k}}=N \cup\left\{0_{k}, n_{k}\right\}$ \\
\hline$T$ & Takım kümesi \\
\hline$M$ & Teknisyen kümesi \\
\hline$Q$ & Teknisyen özellikleri kümesi \\
\hline$L$ & Yetkinlik seviyesi kümesi \\
\hline \multicolumn{2}{|c|}{ Parametreler } \\
\hline$c_{i j}$ & $i$. düğümden $j$. dügüume seyahat mesafesi \\
\hline$t_{i j}$ & $i$. düğümden $j$. düğüme seyahat süresi \\
\hline$\left[\alpha_{i}, \beta_{i}\right]$ & $i$ işinin zaman penceresi \\
\hline$d_{i}$ & $i$ işinin hizmet süresi \\
\hline$[\alpha, \beta]$ & Teknisyenler için zaman penceresi \\
\hline$\rho$ & Takım içindeki teknisyen sayısı \\
\hline$\mu_{i q l}$ & Eğer $i$ işi $l$ seviyesinde $q$ yetkinliği gerektirirse 1 , diğer durumda 0 \\
\hline$\sigma_{m q l}$ & Eğer $m$ teknisyeni $l$ seviyesinde $q$ yetkinliğine sahip ise 1 , diğer durumda 0 \\
\hline$r$ & Mesafe başına enerji tüketimi \\
\hline$\Delta$ & Enerji birimi başına şarj süresi \\
\hline$Y$ & Azami enerji kapasitesi \\
\hline$\theta_{1}$ & Kat edilen mesafe başına maliyet \\
\hline$\theta_{2}$ & Kullanılan araç başına maliyet \\
\hline \multicolumn{2}{|c|}{ Karar değişkenleri } \\
\hline$x_{i j k}$ & Eğer $k$ takımı $i$ işinden $j$ işine giderse 1 , diğer durumda 0 \\
\hline$w_{i k}$ & Eğer $k$ takımı $i$ işine atanırsa 1 , diğger durumda 0 \\
\hline$z_{m k}$ & Eğer $m$ teknisyeni $k$ takımına atanırsa 1 , diğer durumda 0 \\
\hline$y_{i k}$ & $k$ takımının $i$ düğümündeki enerji seviyesi \\
\hline$h_{i k}$ & $k$ takımının $i$. şarj istasyonundan ayrılırken ki enerji seviyesi \\
\hline$\tau_{i k}$ & $k$ takımının $i$ işine başlama zamanı \\
\hline
\end{tabular}


Şarj kısıtları (12-15) ile göz önüne alınmıştır. Araçların herhangi bir düğümdeki enerji seviyesi, enerji tüketimi kısıt (12-13) ile takip edilmektedir. Araçlar şarj istasyonundan ayrılırken şarj seviyeleri batarya kapasitesinden küçük istasyona vardığındaki seviyeden büyük olması için kısıt (14) kullanılmaktadır. Araçların şarj istasyonundaki şarj süresi kısıt (15) ile hesaplanmaktadır. Teknisyenlerin en fazla bir takıma atanması gerektiği kısıt (16) ile tanımlanmaktadır. Her takımda olması gereken teknisyen sayısı ise kısıt (17) ile sağlanmaktadır. İşin gerektirdiği yeterlilik seviyesi ve işe atanan takımdaki teknisyenler beceri birleşimi kısıt (18) ile dikkate alınmaktadır. Başka bir deyişle, takımların işin gereksinimini yerine getirebilecek teknisyenlerden oluşmasını sağlamaktadır. Son olarak kısıt (19-20) sırasıyla ikili ve pozitif değișkenlerin kümesini tanımlamaktadır.

$$
\begin{aligned}
& \sum_{k \in T} w_{i k}=1 \quad \forall i \in B \cup\left\{0_{k}, n_{k}\right\} \\
& \sum_{j \in N_{n_{k}}, i \neq j} x_{i j k}=w_{i k} \forall i \in B \cup\left\{0_{k}, n_{k}\right\}, \forall k \\
& \in T \\
& \sum_{k \in T} \sum_{j \in N_{n_{K^{\prime}}}} x_{i \neq j} \leq 1 \quad \forall i \in F^{\prime} \\
& \sum_{j \in \mathbb{N}_{n_{k}, j \neq j}} x_{0_{k}, j k}=1 \quad \forall k \in T \\
& \sum_{\mathrm{i} \in \mathrm{N}_{0_{k}} \mathrm{i} \neq \mathrm{j}} x_{i n_{k}, k}=1 \quad \forall k \in T \\
& \sum_{\mathrm{j} \in \mathrm{N}_{n_{k}} \mathrm{i} \neq \mathrm{j}} x_{j i k}-\sum_{\substack{\mathrm{i} \in \mathrm{N}_{0_{k}} \mathrm{i} \neq \mathrm{j} \\
\in T, \forall j \in N}} x_{i j k}=0 \quad \forall k \\
& \alpha_{j} \leq \tau_{j k} \leq \beta_{j} \quad \forall \mathrm{k} \in \mathrm{T}, \forall \mathrm{j} \in \mathrm{N}_{0_{k}, n_{k}} \\
& \tau_{i k}+\left(t_{i j}+d_{i}\right) x_{i j k}-\beta_{0_{k}}\left(1-x_{i j k}\right) \\
& \leq \tau_{j k} \quad \forall \mathrm{k} \in \mathrm{T}, \forall \mathrm{i} \\
& \in \mathrm{B}_{0_{k}}, \forall \mathrm{j} \in \mathrm{N}_{n_{k}}, \mathrm{i} \neq \mathrm{j} \\
& \tau_{i k}+\left(t_{i j}+g_{i k}\right) x_{i j k}-\left(\beta_{0_{k}}+\right. \\
& \Delta Y)\left(1-x_{i j k}\right) \leq \tau_{j k} \quad \forall k \in T, \forall i \in \\
& F^{\prime}, \forall j \in N_{n_{k}}, i \neq j
\end{aligned}
$$

$$
\begin{aligned}
& y_{j k} \leq y_{i k}-\left(r d_{i j}\right) x_{i j k}-Y\left(1-x_{i j k}\right) \quad \forall k \\
& \in T, \forall i \in B, \forall j \in N_{n_{k}}, i \\
& \neq j \\
& y_{j k} \leq h_{i k}-\left(r d_{i j}\right) x_{i j k}-Y\left(1-x_{i j k}\right) \forall k \\
& \in T, \forall i \in F_{0_{k}}^{\prime}, \forall j \in N_{n_{k}}, i \\
& \neq j
\end{aligned}
$$

$$
y_{j k} \leq h_{i k} \leq Y \quad \forall k \in T, \forall i \in F_{0_{k}}^{\prime}
$$

$$
g_{i k} \geq \Delta\left(h_{i k}-y_{i k}\right) \leq Y \quad \forall k \in T, \forall i \in F^{\prime}
$$

$$
\sum_{k \in T} z_{m k} \leq 1 \quad \forall m \in M
$$

$$
\sum_{\mathrm{m} \in \mathrm{M}} \mathrm{z}_{\mathrm{mk}}=\rho \quad \forall k \in T
$$

$$
\begin{gathered}
\mu_{i q l} w_{i k} \leq \sum_{m \in M} \sigma_{m q l} z_{m k} \quad \forall k \in T, \forall i \\
\in B, \forall q \in Q, \forall l \in L \\
x_{i j k}, w_{i k}, z_{m k} \in\{0,1\} \quad \forall k \in T, \forall m \\
\in M, \forall i \in \mathrm{N}_{0_{k}}, \forall \mathrm{j} \\
\in \mathrm{N}_{n_{k}}, \mathrm{i} \neq \mathrm{j}
\end{gathered}
$$

$$
\tau_{i k}, y_{i k} \geq 0 \quad \forall k \in T, \forall \mathrm{i} \in \mathrm{N}_{n_{k}}
$$

\subsection{Değișken Komșu Arama Algoritması (Variable Neighbourhood Search Algorithm)}

Değişken Komşu Arama (DKA), Mladenović ve Hansen [36] tarafindan yerel arama algoritması olarak önerilen ve arama uzayındaki yerel tuzaklardan kurtulmak için kullanılan meta-sezgisel bir yöntemdir. Komşuluk yapısının sistematik bir yaklaşımla değişimi DKA algoritmasının temelini teşkil etmektedir. İlk uygulamaları kombinatoryal optimizasyon problemleri olarak hedeflense de tam sayll ve lineer olmayan programlamaya da uygulanmıștır. Konum teorisi, kümeleme analizi, çizelgeleme, araç rotalama, ağ tasarımı, parti büyüklüğü belirleme, yapay zekâ, mühendislik, güvenilirlik, vb. alanlarda başarılı uygulamaları bulunmaktadır [37]. DKA temel olarak 3 basit gözleme dayanmaktadır. 
- Yerel en iyi çözüm diğer komşuluk yapılarına göre yerel bir en iyi çözüm olmak zorunda değildir.

- Global en iyi çözüm tüm olası komşuluk yapılarına göre bir yerel en iyi çözümdür.

- Birçok problem için, bir veya birkaç komşuluk yapısına göre yerel en iyi çözümler göreceli olarak birbirine benzerdir.

DKA yöntemi komşuluk yapısının deterministik ve stokastik değişimini birleştirir. Deterministik kısımdan kasıt yerel aramadır. Herhangi bir başlangıç çözümü kullanılarak, mevcut çözümden tanımlanan komşuluk yapısı ile daha iyi çözüme ulaşmak hedeflenmektedir. Amaç fonksiyonun iyileşmediği durumda yerel arama sezgiseli durur. Stokastik kısım ise herhangi bir komşuluk yapısı kullanılarak yerel minimumlarda sıkışan çözümün bu noktalarda takılmasını önlemek amacıyla kullanılan prosedüre karşılık gelir. Ayrıca, bu kısım mevcut komşuluk yapısı kullanılarak bir noktanın rassal olarak seçimiyle de ifade edilir [38]. DKA algoritmasının akış diyagramı Ek A'da verilmiş̧tir.

DKA algoritmasının başlangıç çözümü sırasıyla şu şekilde üretilmektedir. Müşteriler ilk önce zaman penceresine göre artan bir şekilde sıralanmaktadır. $\mathrm{Bu}$ şekilde ziyaret edilmesi gereken müşteriler zamana göre önceliklendirilmektedir. Bir sonraki aşama olan rotalama aşamasında takımlara sırasıyla müşteriler atanır ve rotalar oluşturulur. Rotalar belirlendikten sonra ise araçların şarj durumları hesaplanır. Eğer gerekli ise rotaya şarj istasyonu eklenir, yani aracın istasyona uğraması sağlanır. Yine benzer şekilde araç herhangi bir istasyona uğramışsa araca yüklenen enerji miktarı hesaplanır. Şarj ile ilgili kararlar verildikten sonra, takımların zaman karar değişkeni hesaplanır. Bir sonraki aşamada zaman penceresi uyumu ve negatif/aşırı şarj durumu ile müşteri ve takımların yetkinliğinin kontrolü yapılır. Bu aşamada bir sapma varsa bu amaç fonksiyonunda cezalandirılır.

DKA algoritması içinde bulunan yerel aramadaki komşuluk yapılarından sırasıyla bahsetmek gerekirse temel olarak yer değiştirme ve ekleme operatörlerini içermektedir. Birinci grup 3 farklı yer değiştirme operatöründen oluşmaktadır, bunlar sırasıyla takım, iş ve şarj istasyonu yerini değiştirerek iyileşme sağlamayı amaçlar. Diğer grupta ise ekleme operatörleri bulunmaktadır. Rasgele seçilen işler aynı veya başka bir rotaya eklenenerek çözüm iyileştirmeye çalışılır. Ayrıca herhangi bir aracın şarjı negatife düşerse amaç fonksiyonuna göre en uygun istasyon seçilerek ilgili rotaya eklenir. Benzer şekilde rotada gereksiz istasyon var ise mevcut rotadan çıkarılır. Yerel arama prosedürünün yerel minimumlarda sıkışması durumunda karıştırma prosedürü için yer değiştirme operatörleri kullanılmaktadır.

\section{Araştırma Sonuçları}

\subsection{Gerçek problem verisi}

Yapılan hesaplamalarda Zamorano ve Stolletz [21] tarafindan kullanılan veri bakım hizmeti sağlayıcısından alınmıştır. Bu veri ile önerilen yöntemin performansı test edilmiştir. Hizmet süresi, zaman penceresi vb. zamana ilişkin veri, bahsi geçen gerçek hayat verisinden aynı dağılımlar kullanılarak üretilmiştir. İlgili makalede olduğu gibi her takımda bulunacak teknisyen sayısı 2 olarak belirlenmiştir. Lokasyonlar arası mesafeler verilmediğinden, makalede olduğu gibi benzer şekilde mesafeler Google Haritalar'dan toplanmıştır [39]. Samsun şehri ve on yedi ilçe gözetilerek müşteriler konumlandırılmıştır. Ayrıca şarj istasyonları şehirdeki mevcut akaryakıt istasyonları gözetilerek içerisine konumlandırılmıştır. Araçların azami kat edebileceği mesafe $160 \mathrm{~km}$ ve $100 \%$ şarj olması için gereken süre $180 \mathrm{dk}$ olarak kabul edilmiştir. [40, 41]. Amaç fonksiyonlarında kullanılan maliyet katsayıları şu şekilde hesaplanmıştır: Kat edilen kilometre maliyeti $\$ 0.06$, bir aracın maliyeti $\$ 60$, bataryayı birim zamanda şarj etmenin maliyeti ise \$0.03 olarak kabul edilmiştir [8]. Kesin sonuçlar Gurobi çözücüsünde çözülmüştür.

\subsection{Deneysel çalışmalar}

Bu bölümde farklı amaç fonksiyonlarına ilişkin sonuçlar sırasıyla verilmiştir. İlk önce modeller Gurobi ile çözülmüş ve sonrasında sezgisel algoritma ile karşılaştırılmıştır. Tablo 2 model 1 'in kesin ve sezgisel algoritma için performans karşılaştırma sonuçlarını içermektedir. Tablo 2 ve 3 'te verilen sapma şu şekilde hesaplanmaktadır.

$$
\text { Sapma }(\%)=\frac{\left(f_{\text {çözüm }}-f_{\text {en iyi çözüm }}\right)}{f_{\text {en iyi çżzüm }}} * 100
$$

Tablo 2. Model 1'e ilişkin karşılaştırma sonuçları

\begin{tabular}{|c|c|c|c|c|c|c|c|c|c|}
\hline \multirow[b]{2}{*}{$\#$} & \multirow[b]{2}{*}{ : } & \multirow[b]{2}{*}{$\underset{\Downarrow}{Z}$} & \multirow[b]{2}{*}{ 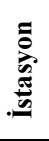 } & \multicolumn{2}{|c|}{ Model 1} & \multicolumn{4}{|c|}{ Sezgisel metot } \\
\hline & & & & Amaç & $\begin{array}{l}\text { Çalışma } \\
\text { zamanı } \\
(\mathrm{sn})\end{array}$ & Amaç & $\begin{array}{l}\text { Sapma } \\
\%\end{array}$ & $\begin{array}{l}\text { Araç } \\
\text { sayısı }\end{array}$ & $\begin{array}{l}\text { Çalışma } \\
\text { zamanı } \\
\text { (sn) }\end{array}$ \\
\hline 1 & 5 & 4 & 3 & 9.23 & 2 & 9.23 & 0.00 & 2 & 418.67 \\
\hline 2 & 5 & 4 & 3 & 9.33 & 2 & 9.33 & 0.00 & 3 & 412.45 \\
\hline 3 & 5 & 4 & 3 & 16.00 & 2 & 16.00 & 0.00 & 2 & 423.07 \\
\hline 4 & 5 & 4 & 3 & 13.50 & 2 & 13.50 & 0.00 & 1 & 420.55 \\
\hline 5 & 10 & 4 & 3 & 16.93 & 2 & 16.95 & 0.14 & 3 & 532.92 \\
\hline 6 & 10 & 4 & 3 & 9.13 & 2 & 9.13 & 0.00 & 3 & 529.54 \\
\hline 7 & 10 & 4 & 3 & 11.13 & 3 & 11.56 & 3.83 & 4 & 517.91 \\
\hline 8 & 10 & 4 & 3 & 8.36 & 2 & 8.36 & 0.00 & 3 & 516.53 \\
\hline 9 & 15 & 4 & 4 & 23.22 & 3 & 23.22 & 0.00 & 3 & 532.49 \\
\hline 10 & 15 & 4 & 4 & 34.90 & 120 & 34.95 & 0.13 & 3 & 608.68 \\
\hline 11 & 15 & 4 & 4 & 21.92 & 2 & 21.94 & 0.10 & 3 & 523.63 \\
\hline 12 & 15 & 4 & 4 & 16.95 & 7200 & 16.91 & -0.22 & 2 & 629.76 \\
\hline 13 & 20 & 4 & 4 & 24.95 & 7200 & 24.35 & -2.41 & 3 & 826.58 \\
\hline 14 & 20 & 4 & 4 & 26.09 & 7200 & 25.19 & -3.45 & 3 & 611.70 \\
\hline 15 & 20 & 4 & 4 & 32.70 & 7200 & 32.63 & -0.20 & 3 & 728.50 \\
\hline 16 & 20 & 4 & 4 & 20.53 & 7200 & 20.53 & -0.01 & 2 & 810.94 \\
\hline 17 & 25 & 6 & 5 & 18.18 & 7200 & 16.91 & -6.93 & 3 & 913.18 \\
\hline 18 & 25 & 6 & 5 & 12.29 & 7200 & 11.45 & -6.84 & 3 & 819.20 \\
\hline 19 & 25 & 6 & 5 & 12.08 & 7200 & 11.24 & -6.96 & 4 & 911.91 \\
\hline 20 & 25 & 6 & 5 & 20.34 & 7200 & 19.23 & -5.43 & 3 & 916.14 \\
\hline 21 & 30 & 6 & 5 & 22.81 & 7200 & 21.37 & -6.30 & 4 & 1100.77 \\
\hline 22 & 30 & 6 & 5 & 14.12 & 7200 & 12.91 & -8.56 & 4 & 1112.23 \\
\hline 23 & 30 & 6 & 5 & 13.89 & 7200 & 12.95 & -6.79 & 4 & 1023.49 \\
\hline 24 & 30 & 6 & 5 & - & 7200 & 25.95 & - & 4 & 993.98 \\
\hline 25 & 35 & 6 & 6 & 10.50 & 7200 & 9.85 & -6.23 & 4 & 1211.05 \\
\hline 26 & 35 & 6 & 6 & 9.76 & 7200 & 9.11 & -6.70 & 5 & 1194.68 \\
\hline 27 & 35 & 6 & 6 & 6.37 & 7200 & 5.61 & -12.00 & 5 & 1213.44 \\
\hline 28 & 35 & 6 & 6 & 6.90 & 7200 & 5.88 & -14.79 & 5 & 1191.68 \\
\hline 29 & 40 & 8 & 6 & 8.35 & 7200 & 7.82 & -6.39 & 6 & 1286.50 \\
\hline 30 & 40 & 8 & 6 & 7.82 & 7200 & 6.94 & -11.26 & 5 & 1262.75 \\
\hline 31 & 40 & 8 & 6 & 8.63 & 7200 & 7.82 & -9.36 & 5 & 1268.61 \\
\hline 32 & 40 & 8 & 6 & 8.11 & 7200 & 7.44 & -8.28 & 6 & 1271.19 \\
\hline
\end{tabular}


Birinci sütunda örnek ismi yer alırken, ikinci, üçüncü ve dördüncü sütunlarda sırasıyla örneklerin içerisindeki iş, araç ve istasyon sayıları belirtilmiştir. Beşinci ve altıncı sütunlarda kesin yönteme ilişkin sonuçlar yer alırken geri kalan sütunlarda sezgisel algoritmaya ilişkin değerler verilmiştir. Kesin algoritma, 24. örneği 7200 saniye içerisinde çözememiş ve herhangi bir değer döndürememiştir. İlk 11 örnek için optimum sonuç bulunabilirken, geri kalan örnekler için uygun çözümler beşinci sütunda verilmiştir. Sezgisel algoritma sonuçları ile kesin yöntem arasındaki fark yüzdelik değer olarak sekizinci sütunda hesaplanmıştır. 5., 7., 10. ve 11. örnekler haricinde sezgisel metot iyileştirme sağlamıştır. Pozitif sapmaların kaynağının kat edilen fazla mesafeden kaynaklandığ aşikârdır. 4. örnek haricinde algoritma birden fazla takım/araç kullanmaktadır.

Tablo 3 model 2'nin kesin ve sezgisel algoritma için performans karşılaştırma sonuçlarını içermektedir. Daha önceden bahsedildiği üzere, model 2'nin amaç fonksiyonu kat edilen mesafenin maliyetiyle takımların kullandığı aracın maliyetiydi. Kesin yöntemle 15., 26., 29., 31. ve 32. örnekler için 2 saat içerisinde bir çözüm döndürülmemiştir ve - işareti ile tabloda gösterilmiştir. Sezgisel yöntem ile 1. ve 4. örnek haricinde iyileştirme sağlandığı sonucuna ulaşılmıştır.

Tablo 3. Model 2'ye ilişkin karşılaştırma sonuçları

\begin{tabular}{|c|c|c|c|c|c|c|c|}
\hline \multirow[b]{2}{*}{ \# } & \multicolumn{3}{|c|}{ Model 2} & \multicolumn{4}{|c|}{ Sezgisel metot } \\
\hline & Amaç & $\begin{array}{l}\text { Araç } \\
\text { sayısı }\end{array}$ & $\begin{array}{l}\text { Çalışma } \\
\text { zamanı } \\
(\mathbf{s n}) \\
\end{array}$ & Amaç & $\begin{array}{l}\text { Sapma } \\
\%\end{array}$ & $\begin{array}{l}\text { Araç } \\
\text { sayısı }\end{array}$ & $\begin{array}{l}\text { Çalışma } \\
\text { zamanı } \\
(\text { sn) }\end{array}$ \\
\hline 1 & 70.51 & 1 & 2 & 70.53 & 0.02 & 1 & 475.45 \\
\hline 2 & 70.54 & 1 & 2 & 70.54 & 0.00 & 1 & 375.59 \\
\hline 3 & 76.84 & 1 & 2 & 76.84 & 0.00 & 1 & 380.67 \\
\hline 4 & 73.50 & 1 & 2 & 73.51 & 0.01 & 1 & 425.10 \\
\hline 5 & 137.28 & 2 & 20 & 137.28 & 0.00 & 2 & 587.97 \\
\hline 6 & 129.23 & 2 & 7200 & 128.30 & -0.72 & 2 & 538.30 \\
\hline 7 & 71.13 & 1 & 2 & 71.13 & 0.00 & 1 & 585.50 \\
\hline 8 & 128.61 & 2 & 2 & 128.25 & -0.28 & 2 & 537.70 \\
\hline 9 & 144.07 & 2 & 7200 & 143.31 & -0.52 & 2 & 488.50 \\
\hline 10 & 155.89 & 2 & 7200 & 154.58 & -0.84 & 2 & 542.40 \\
\hline 11 & 143.05 & 2 & 7200 & 142.57 & -0.34 & 2 & 495.50 \\
\hline 12 & 136.95 & 2 & 7200 & 136.95 & 0.00 & 2 & 594.20 \\
\hline 13 & 205.37 & 3 & 7200 & 205.20 & -0.08 & 3 & 623.42 \\
\hline 14 & 210.93 & 3 & 7200 & 209.92 & -0.48 & 3 & 746.85 \\
\hline 15 & - & - & 7200 & 214.13 & - & 3 & 919.60 \\
\hline 16 & 140.53 & 2 & 7200 & 139.11 & -1.01 & 2 & 764.69 \\
\hline 17 & 200.57 & 3 & 7200 & 198.62 & -0.97 & 3 & 809.66 \\
\hline 18 & 136.69 & 2 & 7200 & 135.97 & -0.53 & 2 & 666.78 \\
\hline 19 & 199.78 & 3 & 7200 & 199.03 & -0.38 & 3 & 917.85 \\
\hline 20 & 264.37 & 4 & 7200 & 264.28 & -0.04 & 4 & 934.61 \\
\hline 21 & 202.33 & 2 & 7200 & 142.01 & -29.81 & 2 & 791.58 \\
\hline 22 & 201.22 & 3 & 7200 & 201.13 & -0.05 & 3 & 1024.29 \\
\hline 23 & 258.27 & 4 & 7200 & 258.00 & -0.10 & 4 & 936.16 \\
\hline 24 & 203.04 & 3 & 7200 & 202.55 & -0.24 & 3 & 835.92 \\
\hline 25 & 255.94 & 4 & 7200 & 255.02 & -0.36 & 4 & 1063.10 \\
\hline 26 & - & - & 7200 & 318.49 & - & 5 & 977.22 \\
\hline 27 & 260.56 & 4 & 7200 & 260.08 & -0.18 & 4 & 1070.74 \\
\hline 28 & 252.66 & 4 & 7200 & 252.20 & -0.18 & 4 & 1343.30 \\
\hline 29 & - & - & 7200 & 321.63 & - & 5 & 1189.70 \\
\hline 30 & 379.51 & 6 & 7200 & 379.46 & -0.01 & 6 & 1280.91 \\
\hline 31 & - & - & 7200 & 258.43 & - & 4 & 1340.85 \\
\hline 32 & - & - & 7200 & 193.18 & - & 3 & 1252.95 \\
\hline
\end{tabular}

Modellerin kullandığı araç sayıları Tablo 4 'te verilmiştir. Model 1 ortalamada 3.53 araç kullanırken model 2 ise ortalama 2.78 araç ile müşterilere ulaşmaktadır. Bu sonuçlar ayrıca atanan teknisyen sayısını da dolaylı olarak göstermektedir. Her bir araçta iki teknisyen olduğu hatırlanacak olursa model 2 ortalamada 5.56 çalışan ile tüm işlerin yapılmasını sağlamaktadır.

Problemde farklı amaç fonksiyonları kullanarak toplam mesafe minimizasyonunun yanı sıra, araç maliyeti de dikkate alınmıştır. Bu sayede farklı maliyet faktörlerinin problemi zorlaştırdığı görülmüştür. Esasında, şarj istasyonlarının kullanım gerekliliği ve bu istasyonlarının doğru konumlandırılması gerektiği de problemi doğrudan etkileyen operasyonel kararlardandır. Ayrıca, kesin çözüm yöntemi ile bazı problemlerin çözülemediği de dikkate alınırsa, geliştirilen DKA algoritması makul sürede iyi sonuçlar verdiği anlaşılmaktadır. Gerçek hayat verisinden üretilen veri seti ile elde edilen sonuçlar bize elektrikli araçların bakım hizmeti sağlayan firmalarda günlük kullanılabilirliğini göstermiştir.

Tablo 4. Modellere ilişkin kullanılan araç/takım sayısı

\begin{tabular}{|c|c|c|}
\hline$\#$ & Model 1 & Model 2 \\
\hline 1 & 2 & 1 \\
\hline 2 & 3 & 1 \\
\hline 3 & 2 & 1 \\
\hline 4 & 1 & 1 \\
\hline 5 & 3 & 2 \\
\hline 6 & 3 & 2 \\
\hline 7 & 4 & 1 \\
\hline 8 & 3 & 2 \\
\hline 9 & 3 & 2 \\
\hline 10 & 3 & 2 \\
\hline 11 & 3 & 2 \\
\hline 12 & 2 & 2 \\
\hline 13 & 3 & 3 \\
\hline 14 & 3 & 3 \\
\hline 15 & 3 & 3 \\
\hline 16 & 2 & 2 \\
\hline 17 & 3 & 3 \\
\hline 18 & 3 & 2 \\
\hline 19 & 4 & 3 \\
\hline 20 & 3 & 4 \\
\hline 21 & 4 & 2 \\
\hline 22 & 4 & 3 \\
\hline 23 & 4 & 4 \\
\hline 24 & 4 & 3 \\
\hline 25 & 4 & 4 \\
\hline 26 & 5 & 5 \\
\hline 27 & 5 & 4 \\
\hline 28 & 5 & 4 \\
\hline 29 & 6 & 5 \\
\hline 30 & 5 & 6 \\
\hline 31 & 5 & 4 \\
\hline 32 & 6 & 3 \\
\hline Ortalama & 3.53 & 2.78 \\
\hline
\end{tabular}




\section{Sonuç}

$\mathrm{Bu}$ çalışmada sürdürülebilir işgücü çizelgeleme ve rotalama problemi (S-İÇRP) ARP'nin uzantısı olarak ortaya konulmuştur. Problemde amaç toplam mesafe minimizasyonunun yanı sıra, araç yatırım maliyetini de en aza indirmeyi içermektedir. Ele alınan problemin çözümünde iki farklı amaç fonksiyonu göz önüne alınmış ve farklı amaçlar altında sonuçların etkileri gözlemlenmiştir. Geliştirilen sezgisel yöntem ise E-TRÇP'nin etkin bir şekilde çözebileceğini göstermiştir. Farklı amaç fonksiyonları ile deneysel çalışmalar yapılmıştır. Gurobi çözücüsünün bazı problemleri çözemediği gözlemlenirken DKA'nın makul sürede iyi çözümler ürettiği sonucuna varılmıştır. Gerçek hayat verisinden üretilen veri seti ile elde edilen sonuçlar bize elektrikli araçların bakım hizmeti sağlayan firmalarda günlük kullanılabilirliğini göstermiştir. $\mathrm{Bu}$ duruma ek olarak, şarj istasyonu için konum belirlenmesi ayrıca stratejik karar vermede önemlidir çünkü elektrikli araçların kullanımı mevcut teknoloji seviyesinde istasyondan bağımsız düşünülemez. Araçların menzili arttıkça da bu bağımlılığın ortadan kalkacağı aşikârdır.

\section{Çıkar çatışması}

Yazarlar çıkar çatışması olmadığını beyan etmektedir.

\section{Benzerlik oranı (iThenticate): \% 18}

\section{Kaynaklar}

[1] O. Kherbash ve M. L. Mocan, "A Review of Logistics and Transport Sector as a Factor of Globalization," Procedia Economics and Finance, vol. 27, pp. 42-47, 2015/01/01/ 2015, doi: https://doi.org/10.1016/S22125671(15)00969-7.

[2] T. Haasz vd., "Perspectives on decarbonizing the transport sector in the EU-28," Energy Strategy Reviews, vol. 20, pp. 124-132, 2018/04/01/ 2018, https://doi.org/10.1016/j.esr.2017.12.007.

[3] R. Engström, "The Roads' Role in the Freight Transport System," Transportation Research Procedia, vol. 14, pp. 1443-1452, 2016/01/01/ 2016, https://doi.org/10.1016/ j.trpro.2016.05.217.

[4] EU-SCIENCE-HUB. "Transport sector economic analysis." https://ec.europa.eu/jrc/en/research-topic/ transport-sector-economic-analysis (accessed 01.04.2020.

[5] (2014). Technical report No 09/2014 Annual European union greenhouse gas inventory 1990-2012 and inventory report 2014.

[6] European Comission "Report from the comission to the European parliament and the council-Progress towards achieving the Kyoto and EU2020 objecitves.," European Comission., 2014.

[7] European-Commission, "WHITE PAPER Roadmap to a Single European Transport Area - Towards a competitive and resource efficient transport system," ed, 2011.

[8] M. Schiffer ve G. Walther, "The electric location routing problem with time windows and partial recharging," European Journal of Operational
Research, vol. 260, no. 3, pp. 995-1013, 8/1/ 2017, https://doi.org/10.1016/j.ejor.2017.01.011.

[9] G. Suizo. "Large \& recharged: Top electric vehicles." https://www.greenfleetmagazine.com/ 155563/largerecharged-top-electric-fleets (Accessed 01.05.2020).

[10] A. T. Ernst, H. Jiang, M. Krishnamoorthy, B. Owens, ve D. Sier, "An Annotated Bibliography of Personnel Scheduling and Rostering," (in English), Ann Oper Res, vol. 127, no. 1-4, pp. 21-144, 2004/03/01 2004, doi: 10.1023/B:ANOR.0000019087.46656.e2.

[11] A. T. Ernst, H. Jiang, M. Krishnamoorthy, ve D. Sier, "Staff scheduling and rostering: A review of applications, methods and models," European Journal of Operational Research, vol. 153, no. 1, pp. 3-27, 2004/02/16/ 2004, https://doi.org/10.1016/S03772217(03)00095-X.

[12] J. Van den Bergh, J. Beliën, P. De Bruecker, E. Demeulemeester, ve L. De Boeck, "Personnel scheduling: A literature review," European Journal of Operational Research, vol. 226, no. 3, pp. 367-385, 5/1/ 2013, http://dx.doi.org/10.1016/j.ejor. 2012.11.029.

[13] J. A. Castillo-Salazar, D. Landa-Silva, ve R. Qu, "Workforce scheduling and routing problems: literature survey and computational study," (in English), Ann Oper Res, pp. 1-29, 2014/08/14 2014, doi: 10.1007/s 10479-014-1687-2.

[14] J.-F. Cordeau, G. Laporte, F. Pasin, ve S. Ropke, "Scheduling technicians and tasks in a telecommunications company," Journal of Scheduling, vol. 13 , no. 4, pp. 393-409, 2010/08/01 2010, doi: 10.1007/s10951-010-0188-7.

[15] A. A. Kovacs, S. N. Parragh, K. F. Doerner, ve R. F. Hartl, "Adaptive large neighborhood search for service technician routing and scheduling problems," Journal of Scheduling, vol. 15, no. 5, pp. 579-600, 2012/10/01 2012, doi: 10.1007/s10951-011-0246-9.

[16] A. Lim, B. Rodrigues, ve L. Song, "Manpower allocation with time windows," Journal of the Operational Research Society, vol. 55, no. 11, pp. 1178-1186, 2004/11/01 2004, doi: 10.1057/palgrave.jors.2601782.

[17] Y. Li, A. Lim, ve B. Rodrigues, "Manpower allocation with time windows and job-teaming constraints," Naval Research Logistics (NRL), vol. 52, no. 4, pp. 302-311, 2005, doi: 10.1002/nav.20075.

[18] A. Dohn, E. Kolind, ve J. Clausen, "The manpower allocation problem with time windows and job-teaming constraints: A branch-and-price approach," Computers \& Operations Research, vol. 36, no. 4, pp. 1145-1157, 2009/04/01/ 2009, https://doi.org/10.1016/ j.cor.2007.12.011.

[19] J. Xu ve S. Y. Chiu, "Effective Heuristic Procedures for a Field Technician Scheduling Problem," Journal of Heuristics, vol. 7, no. 5, pp. 495-509, 2001/09/01 2001, doi: 10.1023/A:1011377929184.

[20] V. Pillac, C. Guéret, ve A. L. Medaglia, "A parallel matheuristic for the technician routing and scheduling problem," Optimization Letters, vol. 7, no. 7, pp. 1525- 
1535, 2013/10/01 2013, doi: 10.1007/s11590-0120567-4.

[21] E. Zamorano ve R. Stolletz, "Branch-and-price approaches for the Multiperiod Technician Routing and Scheduling Problem," European Journal of Operational Research, vol. 257, no. 1, pp. 55-68, 2017/02/16/ 2017, doi: https://doi.org/10.1016/ j.ejor.2016.06.058.

[22] M. Erdem, "Elektrikli Araçla Periyodik Teknisyen Rotalama ve İstasyon Yeri Seçim Problemi," Avrupa Bilim ve Teknoloji Dergisi , Ejosat, no. Special issue, pp. 16-27, 2020, doi: 10.31590/ejosat.818352.

[23] S. Erdoğan ve E. Miller-Hooks, "A Green Vehicle Routing Problem," Transportation Research Part E: Logistics and Transportation Review, vol. 48, no. 1, pp. 100-114, 1// 2012, https://doi.org/10.1016/j.tre. 2011.08.001.

[24] M. Schneider, A. Stenger, ve D. Goeke, "The Electric Vehicle-Routing Problem with Time Windows and Recharging Stations," Transportation Science, vol. 48, no. 4, pp. 500-520, 2014, doi: 10.1287/trsc.2013.0490.

[25] R. G. Conrad ve M. A. Figliozzi, "The Recharging Vehicle Routing Problem," in Industrial Engineering Research Conference, T. Doolen and E. V. Aken, Eds., 2011.

[26] J. Hof, M. Schneider, ve D. Goeke, "Solving the battery swap station location-routing problem with capacitated electric vehicles using an AVNS algorithm for vehiclerouting problems with intermediate stops," Transportation Research Part B: Methodological, vol. 97, pp. 102-112, 2017/03/01/ 2017, https://doi.org/ 10.1016/j.trb.2016.11.009.

[27] D. Goeke ve M. Schneider, "Routing a mixed fleet of electric and conventional vehicles," European Journal of Operational Research, vol. 245, no. 1, pp. 81-99, 2015/08/16/ 2015, http://dx.doi.org/10.1016/ j.ejor.2015.01.049.

[28] G. Desaulniers, F. Errico, S. Irnich, ve M. Schneider, "Exact Algorithms for Electric Vehicle-Routing Problems with Time Windows," Operations Research, vol. 64, no. 6, pp. 1388-1405, 2016, doi: 10.1287/opre.2016.1535.

[29] G. Hiermann, J. Puchinger, S. Ropke, ve R. F. Hartl, "The Electric Fleet Size and Mix Vehicle Routing Problem with Time Windows and Recharging Stations," European Journal of Operational Research, vol. 252, no. 3, pp. 995-1018, 2016/08/01/ 2016, http://dx.doi.org/10.1016/j.ejor.2016.01.038.

[30] Á. Felipe, M. T. Ortuño, G. Righini, ve G. Tirado, "A heuristic approach for the green vehicle routing problem with multiple technologies and partial recharges," Transportation Research Part E: Logistics and Transportation Review, vol. 71, pp. 111-128, 2014/11/01/ 2014, http://dx.doi.org/10.1016/ j.tre.2014.09.003.

[31] M. Keskin ve B. Çatay, "Partial recharge strategies for the electric vehicle routing problem with time windows," Transportation Research Part C: Emerging Technologies, vol. 65, pp. 111-127, 4// 2016, https://doi.org/10.1016/j.trc.2016.01.013.

[32] M. Erdem ve Ç. Koç, "Analysis of electric vehicles in home health care routing problem," Journal of Cleaner Production, vol. 234, pp. 1471-1483, 2019/10/10/2019, https://doi.org/10.1016/j.jclepro. 2019.06.236.

[33] S. Pelletier, O. Jabali, ve G. Laporte, "50th Anniversary invited article-Goods distribution with electric vehicles: review and research perspectives," Transportation Science, vol. 50 (1), pp. 3-22, 2016.

[34] S. Pelletier, O. Jabali, G. Laporte, ve M. Veneroni, "Battery degradation and behaviour for electric vehicles: Review and numerical analyses of several models," Transportation Research Part B: Methodological, vol. 103, pp. 158-187, 2017/09/01/ 2017, https://doi.org/10.1016/ j.trb.2017.01.020.

[35] M. Schiffer, M. Schneider, ve G. Laporte, "Designing sustainable mid-haul logistics networks with intraroute multi-resource facilities," European Journal of Operational Research, vol. 265, no. 2, pp. 517-532, 2018/03/01/ 2018, https://doi.org/10.1016/j.ejor. 2017.07.067.

[36] N. Mladenović ve P. Hansen, "Variable neighborhood search," Computers \& Operations Research, vol. 24, no. 11, pp. 1097-1100, 1997/11/01/ 1997, http://dx.doi.org/10.1016/S0305-0548(97)00031-2.

[37] P. Hansen, N. Mladenović, J. Brimberg, ve J. A. M. Pérez, "Variable Neighborhood Search," in Handbook of Metaheuristics, M. Gendreau and J.-Y. Potvin Eds. Boston, MA: Springer US, 2010, pp. 61-86.

[38] P. Hansen ve N. Mladenović, "Variable neighborhood search: Principles and applications," European Journal of Operational Research, vol. 130, no. 3, pp. 449-467, 5/1/ 2001, http://dx.doi.org/10.1016/S03772217(00)00100-4.

[39] Google. "The Google Maps Distance Matrix API." https://developers.google.com/maps/documentation/di stance-matrix/intro (Accessed 01.05.2020).

[40] S. Edelstein. "2017 electric cars with more than 100 miles of range (updated)." Green car reports. https://www.greencarreports.com/news/1107455_201 7-electric-cars-with-more-than-100-miles-of-range (Accessed 01.01.2018).

[41] E. Schmidt. "Battery Electric Cars Reported Range Comparison." https://www.fleetcarma.com/2017battery-electric-cars-reported-range-comparison/ (Accessed 01.05.2020).

[42.] Ramos, J., Padrón, S., Guillén, L., Piera, M., Guimarans, D., ve Herrero, R. Intelligent platform for sustainable routing, 2010, https://www.researchgate.net/publication/236455075_ Intelligent_platform_for_sustainable_routing (Accessed 01.12.2021). 


\section{Ekler}

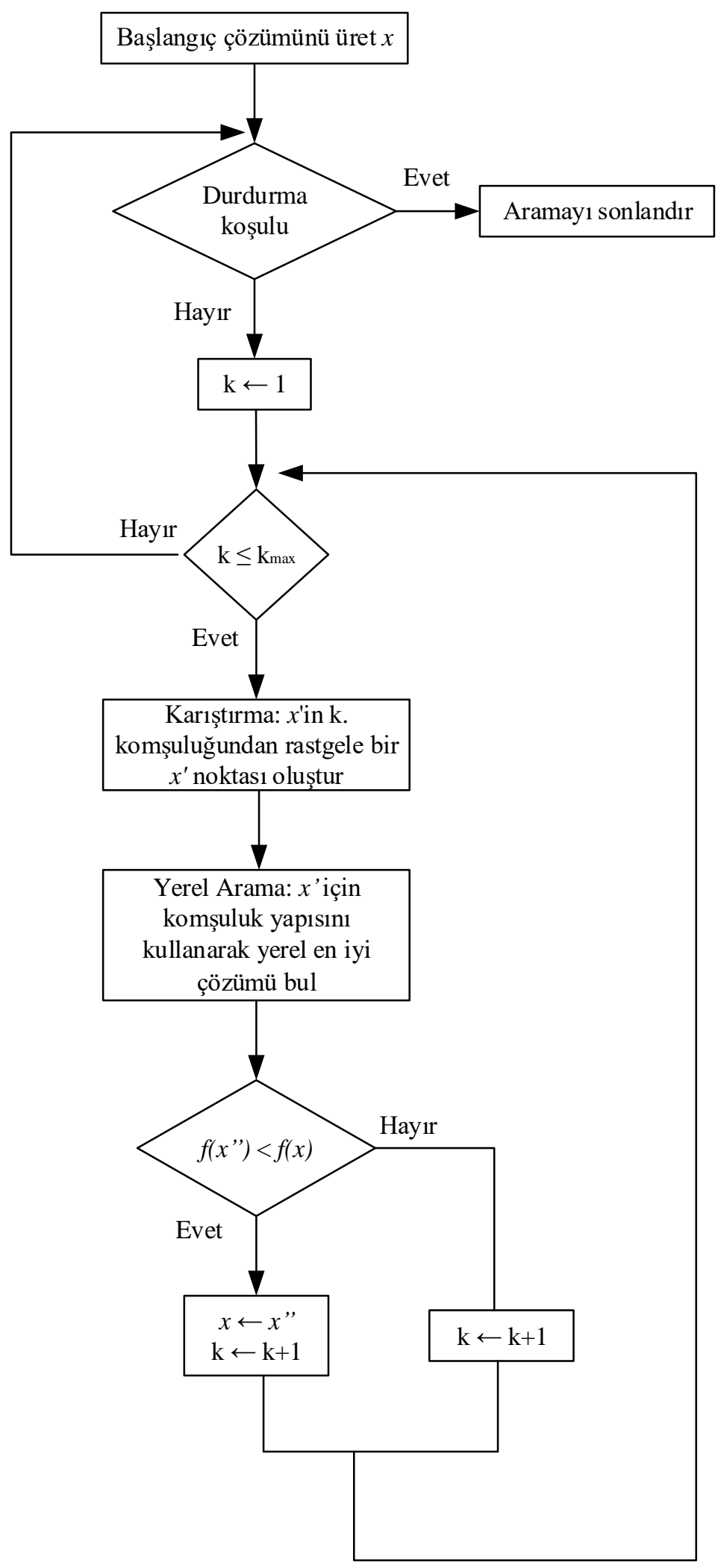

Şekil A.1. DKA akış diyagramı [42] 